\title{
QSB application in LP teaching of operational research Shucheng Xiao ${ }^{1, \mathrm{a}}$, Shan $\mathrm{Qiu}^{2}$, Zhendong Yang ${ }^{1}$ and Jinlan Qiao ${ }^{1}$ \\ ${ }^{1}$ Chongqing Logistical Engineering University, China; \\ ${ }^{2}$ Chongqing University of Posts and Telecommunications, China. \\ axiaosc@cqu.edu.cn
}

Keywords: operations research; practical teaching; QSB; linear programming.

\begin{abstract}
This article in view of the current problems in operations research teaching that teaching is from the practical application, and put forward the QSB software was applied to this course teaching, then the software used in linear programming line of classroom teaching. Through the use of this method, improve the teaching efficiency, also make teaching content more close to the practical application, provides a new choice for operations research teaching.
\end{abstract}

\section{Introduction}

Linear programming $^{[1,2]}$ is the important content of the operations research course, and that can help the student to improve the ability of solving problems by practice between teacher and students. But in actual implementation, teachers usually adopt teaching methods and the algorithm is proved that the interpretation of theory. Through a semester of learning, the teacher to complete the teaching content of the textbook, the students learned the teacher speak in class. But the students' ability to really use operations research to solve practical problems or is very poor, even cannot be applied to solve practical problems. ${ }^{[2-7]}$

Why is this case? There are many reasons, but I think the results of excessive pay attention to the ideal model of operation is an important reason. Teaching in order to perfect and ignore the most important thing is combined with the practical application. In fact, the teacher is aware of the problem in the teaching, but due to the limitation of time and teaching means, teaching process in order to highlight the principle, algorithm and the model of idealized. If the teacher in the classroom for a model of further discussion, gradually close to the actual problem, computing becomes rather complicated, for classroom teaching, this is often not control. To solve this contradiction, in the teaching process into handy tools are very necessary, this paper applies QSB(Quantitative Systems for Business) software to linear programming teaching as an example for discussion of this problem. ${ }^{\text {[8-10] }}$

\section{QSB solve linear programming in class}

\subsection{Linear programming problem.}

The following is a case ${ }^{[2]}$ of linear programming case describes:

In prepare for the winter season, a clothing company is manufacturing parka and goose overcoats, insulated pants, and gloves. All products are manufactured in four different departments: cutting, insulating, sewing, and package. The company has receive firm orders for its products. The contract stipulates a penalty for undelivered items. Devise an optimal production plan for the company based on the following data:

\begin{tabular}{|c|c|c|c|c|c|}
\hline \multirow[b]{2}{*}{ department } & \multicolumn{4}{|c|}{ Time per 100 units(hr) } & \multirow[b]{2}{*}{ capacity } \\
\hline & parka & goose & pants & gloves & \\
\hline Cutting & 35 & 30 & 25 & 15 & 10000 \\
\hline Insulating & 25 & 35 & 30 & 10 & 10000 \\
\hline Sewing & 45 & 35 & 40 & 22 & 10000 \\
\hline Packaging & 15 & 15 & 10 & 5 & 10000 \\
\hline Demand & 8500 & 8000 & 6500 & 5500 & \\
\hline Uini profit(\$) & 30 & 40 & 20 & 10 & \\
\hline Unit penalty $(\$)$ & 15 & 20 & 10 & 8 & \\
\hline
\end{tabular}


Mathematical Model: the variables of the case are $x_{1}, x_{2}, x_{3}, x_{4}$, They represent respectively parka,goose,pants and gloves numbers.

The company is penalized for not meeting demand.So the objective ismaximized the net profit.,defined as

Net profit=Total profit- Total penalized

The total prifit is $30 x_{1}+40 x_{2}+20 x_{3}+10 x_{4}$, To compute the Total penalized, the new variable $s_{j}$ represent the shortage in demand for product $j$, the demand constraints can be written as:

$x_{1}+\mathrm{s}_{1}=8500, x_{2}+\mathrm{s}_{2}=8000, x_{3}+\mathrm{s}_{3}=6500, x_{4}+\mathrm{s}_{4}=5500$,

$x_{i} \geq 0, \quad s_{j} \geq 0, i, j=1,2,3,4$

the total penalized can be comput as: $15 \mathrm{~s}_{1}+20 \mathrm{~s}_{2}+10 \mathrm{~s}_{3}+8 \mathrm{~s}_{4}$,

So the complete model is:

Maximize $\mathrm{z}=30 \mathrm{x}_{1}+40 \mathrm{x}_{2}+20 \mathrm{x}_{3}+10 \mathrm{x}_{4},-\left(15 \mathrm{~s}_{1}+20 \mathrm{~s}_{2}+10 \mathrm{~s}_{3}+8 \mathrm{~s}_{4,}\right)$

Subject to

$$
\begin{aligned}
& .35 x_{1}+.30 x_{2}+.25 x_{3}+.15 x_{4} \leq 10000 \\
& .25 x_{1}+.35 x_{2}+.30 x_{3}+.10 x_{4} \leq 10000 \\
& .45 x_{1}+.35 x_{2}+.40 x_{3}+.22 x_{4} \leq 10000 \\
& .15 x_{1}+.15 x_{2}+.10 x_{3}+.05 x_{4} \leq 10000 \\
& x_{1}+s_{1}=8500, x_{2}+s_{2}=8000, x_{3}+s_{3}=6500, x_{4}+s_{4}=5500 \\
& x_{i} \geq 0, \quad s_{j} \geq 0, i, j=1,2,3,4
\end{aligned}
$$

Solution:

Here the results maybe from the calculation results before class, maybe can be a homework. Why? because the model finished,or Computing will waste a lot of time in class. It is OK? No! the students should learn more. How to do then.

For most of the students, it may not have entered the state. Thus we should teach more, to make the

\begin{tabular}{|c|c|c|c|c|c|c|}
\hline $\begin{array}{c}08-09-2016 \\
11: 06: 44\end{array}$ & $\begin{array}{l}\text { Decision } \\
\text { Variable }\end{array}$ & $\begin{array}{l}\text { Solution } \\
\text { Value }\end{array}$ & $\begin{array}{c}\text { Unit Cost or } \\
\text { Profit C[i] }\end{array}$ & $\begin{array}{c}\text { Total } \\
\text { Contribution }\end{array}$ & $\begin{array}{c}\text { Reduced } \\
\text { Cost }\end{array}$ & $\begin{array}{l}\text { Basis } \\
\text { Status }\end{array}$ \\
\hline 1 & $\times 1$ & $8,500.0000$ & 30.0000 & $255,000.0000$ & 0 & basic \\
\hline 2 & $\times 2$ & $8,000.0000$ & 40.0000 & $320,000.0000$ & 0 & basic \\
\hline 3 & $\times 3$ & $5,412.5010$ & 20.0000 & $108,250.0000$ & 0 & basic \\
\hline 4 & $\times 4$ & $5,500.0000$ & 10.0000 & $55,000.0000$ & $\mathbf{0}$ & basic \\
\hline 5 & $\times 5$ & 0 & -15.0000 & 0 & -11.2500 & at bound \\
\hline 6 & $\times 6$ & $\mathbf{0}$ & -20.0000 & $\mathbf{0}$ & -33.7500 & at bound \\
\hline 7 & 87 & $1,087.5000$ & -10.0000 & $-10,875.0000$ & $\mathbf{0}$ & basic \\
\hline \multirow[t]{2}{*}{8} & $\times 8$ & 0 & -8.0000 & 0 & -1.5000 & at bound \\
\hline & Objective & Function & [Max. $]=$ & $727,375.0000$ & & \\
\hline
\end{tabular}
model more close to practical application, now we'll have to use tools to achieve a goal.

\subsection{QSB solve linear programming problem.}

QSB is a kind of teaching software, using QSB tool in class, we can use two minutes to solve the model. Firstly, put the model parameters into the LP-ILP of QSB,

Secondly, click the run button, the result will be getting at once, as shown in the figure 1 .

Figure 1 solution of the problem

This command shows the solution of the problem. It includes the decision variable value, contribution to the objective, and reduced cost of each decision variable. This also indicates the status of whether the decision variable is on the final basis. 


\section{Discuss linear programming problem more by QSB.}

If you want to learn more about the production planning and inventory control model, we can get more information from the combined report.

Choose the commands from the Results Menu -> Combined Report.to display the appropriate results. This command shows the combined report of the problem. It includes the solution value, contribution to the objective, reduced cost, and range of optimality for each decision variable, and right-hand side, surplus or slack, shadow price, and range of feasibility for each constraint.

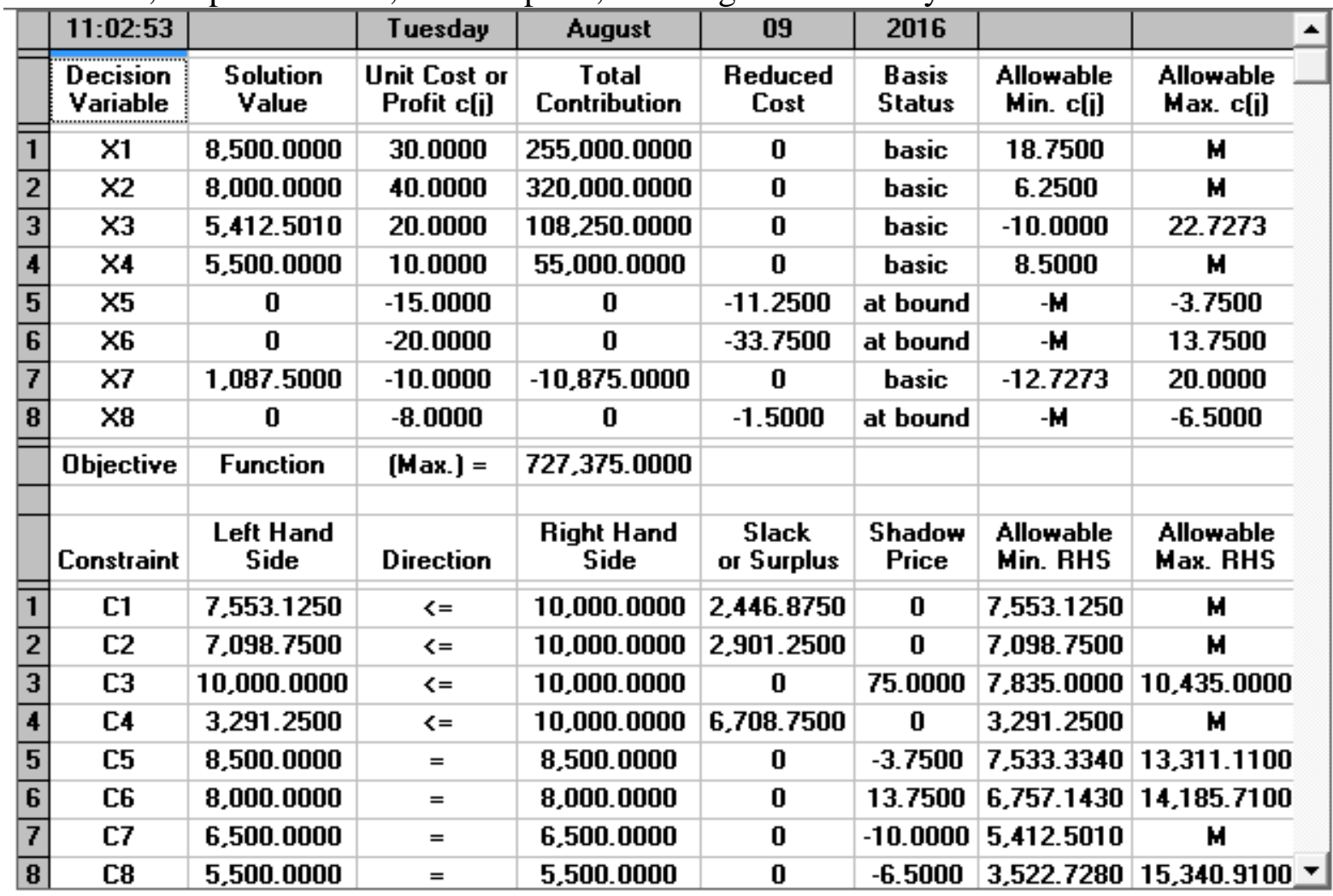

Figure 2 the combined report of the problem

From the result we can see that the total net profit was 727357 dollar, These pants does not meet the requirements, is 1087.5, the punishment, 10875 dollar. For the resources of the factory, the sewing is exhausted, slacks to 0 . From these data, we can further discuss the model:

(a) If the company should intensify the building of its own resources, which should invest more in a workshop?

From profit maximization, obviously, should the sewing construction, improve the production hours;

(b) If possible, cooperate with other companies, should take what kind of production outsourcing, outsourcing cost control for how many appropriate?

Also, as a result, through the picture in order to meet the demand, can put the pants outsourcing, outsourcing cost should be less than $\$ 20+\$ 10=\$ 30$.

In addition to these problems, we can discuss more problems associated with practical applications. Through the use of QSB tools, greatly enriched our teaching contents, improve the students' interest in learning, stimulate students desire to solve practical problems and establish the confidence of theory with practice.

\section{Summary}

The LP is an important part of the operations research teaching. Through study and discussion of the LP model can improve the student ability of solving practical problems. But in the classroom teaching, teachers tend to design the ideal case, to set up the ideal model, to solve the model, to complete the "perfect" teaching link. Students in the learning process can't experience the practical 
application of the model This paper argues that the reason was that the teacher was teaching time and teaching content restrictions, If the QSB applied in classroom teaching, can greatly improve the situation. In this paper, through the examples show that the teaching of linear programming, with the tools of QSB, can make the combination of the teaching process is convenient and practical application, and extending the model more practical.

\section{References}

[1]. Hooker J N. Chapter 15 - Operations Research Methods in Constraint Programming: Foundations of Artificial Intelligence[Z]. Francesca Rossi P V B A. Elsevier, 2006: Volume 2, 527-570.

[2]. Taha H A. Operations Research:An Introduction(Ninth Edition)[Z]. Beijing: China Renmin University Press, 2014405-440.

[3]. Ruxue Wu. Introducing "collaborative learning" into the teaching of operational research [J]. Journal of Guangxi University(Natural Science Edition). 2006(S1).

[4]. BAO Lin, PAN Wei-wei, XIE Yong-hong. Study on the strengthening practice teaching of operational research in Economic management professional [J]. Journal of Hebei University of Engineering(Social Science Edition) . 2014(01).

[5]. LIU Xia, LIU Yan-wei. Mode Analysis of Operational Research Curriculum Instruction and Reform [J]. Journal of Heilongjiang College of Education. 2012(05).

[6]. GUO Xiu ying. A Study on Teaching Strategy on Operational Research forEconomics and Management Majors [J]. Journal of Southwest Petroleum University(Social Sciences Edition). 2012(02).

[7]. Zheng Yue;Hong Yunfei;Zhang Tao;Cheng Zhong;Qin Chao. Teaching Reform Research on 《Operational Research》 Course under the Transformation and Development in Undergraduate Universities and Colleges [J]. Journal of Yangtze University(Natural Science Edition). 2015(22).

[8]. Xiao S, Wu J, He H, et al. An Emergency Logistics Transportation Path Optimization Model by Using Trapezoidal Fuzzy[J]. 2014 11TH INTERNATIONAL CONFERENCE ON FUZZY SYSTEMS AND KNOWLEDGE DISCOVERY (FSKD). 2014: 199-203.

[9]. Xiao S, Wu J, He E, et al. Identification of software NFR based on the fuzzy-QFD model[J]. International Journal of Security and its Applications. 2015, 9(11): 145-154.

[10]. YU Shi-hang,ZHANG Shui-sheng,ZHANG Liang-yong. Applying the idea of mathematical modeling to the teaching of the course of operational research [J]. Journal of Science of Teachers' College and University. 2009(06). 